\title{
IDENTIFIKASI KOMODITAS UNGGULAN DESA UNTUK MENGEMBANGKAN BADAN USAHA MILIK DESA (BUMDES) DI DESA SEMAMUNG KABUPATEN SUMBAWA
}

\author{
Identification of a Village Leading Commodities to Develop Public Owned Rural Enterprise \\ (Bumdes) in the Village of Semamung, Sumbawa Regency
}

\author{
Muhammad Nurjihadi ${ }^{1}$, Edi Irawan ${ }^{1}$, Abdul Hadi Ilman ${ }^{1}$ \\ 1Program Studi Ekonomi Pembangunan, Fakultas Ekonomi dan Bisnis Universitas Teknologi Sumbawa
}

Email: $\underline{\text { m.nurjihadi@uts.ac.id }}$

\begin{abstract}
The program of Village's Fund from the central government commanded villages government and their society to develop public owned rural enterprises in order to reduce rural poverty. However, many villages unable to develop the rural enterprises since they have no idea related to their own potential. Therefore, it needs scientific approach to help the villagers to understand their own potential. This research is designed to observe the leading commodities in SemamungVillage of Sumbawa as a case study. This research is using Analytical Hierarchy Process (AHP) as a tool of analysis. The research result revealed that there are three main categories of the village economic activity in Semamung. Each category has its own leading commodity based on the perception of the villagers themselves. The first category is On Farm Agriculture category, the leading commodity for this category is rice cultivation. The second category is Non Farm Agriculture Category, traditional livestok of cattle is the leading commodity for this category. The last category is Rural Services Category and its leading commodity is laundry service.
\end{abstract}

Keywords: Leading commodities, Rural enterprises, AHP.

\section{Latar Belakang}

Salah satu poin penting dari gagasan Nawacita pemerintahan Presiden Joko Widodo dan Wakil Presiden Muhammad Jusuf Kalla adalah "membangun Indonesia dari pinggiran dengan memperkuat daerah-daerah dan desa". Konsep in menempatkan desa sebagai garda terdepan pembangunan bangsa. Hal ini juga diperkuat dengan disahkannya UU No 6 tahun 2014 tentang Desa yang pada prinsipnya memberikan kewenangan yang lebih luas kepada desa untuk merencanakan, melaksanakan dan mengevaluasi proses pembangunannya sendiri. Salah satu amanat dari UU tersebut adalah adanya Dana Alokasi Desa yang salah satu sasaran penggunaannya adalah membangun dan mengembangkan Badan Usaha Milik Desa (BUMDes) sebagai sarana untuk meningkatkan kesejahteraan masyarakat desa. Dengan demikian, BUMDes yang dibangun harus berorientasi pada potensi, kebutuhan dan keunggulan lokal di desa agar memiliki multiplier effect yang signifikan terhadap perekonomian desa. Akan tetapi, banyak desa yang tidak mampu mengidentifikasi apa keunggulan desa mereka sehingga menyulitkan mereka untuk membangun BUMDes.

Potensi dan keunggulan desa dapat dilihat dari keberadaan komoditas unggulan di desa tersebut. Daryanto dan Hafizrianda (2010) menjelaskan bahwa suatu komoditas dapat disebut sebagai komoditas unggulan suatu wilayah apabila komoditas tersebut mampu menjadi penggerak utama (prime mover) pembangunan ekonomi di wilayah tersebut, mempunyai keterkaitan (linkage) ekonomi yang kuat baik ke depan maupun ke belakang, mampu menyerap tenaga kerja secara optimal serta dapat bertahan dalam jangka panjang. Untuk mengidentifikasi komoditas apa saja yang memiliki kriteria tersebut, beberapa alat pengukuran dapat digunakan seperti Rassmussen's dual criterion yang mendasarkan analisisnya pada nilai forward and backward linkage dari suatu sektor dalam tabel Input-Output (IO). Selain itu, komoditas unggulan juga dapat diidentifikasi dengan melakukan scoring menggunakan Analisis Hirarki Proses (AHP). Meski demikian, analisis IO tidak mungkin dilakukan dalam mengidentifikasi komoditas unggulan desa mengingat tidak adanya data IO tingkat desa. Oleh karenanya, analisis AHP lebih populer digunakan untuk mengidentifikasi komoditas unggulan pada tingkat yang lebih rendah dari tingkat kabupaten.

Pengukuran komoditas unggulan menggunakan teknik AHP memberikan informasi yang lebih valid dari pada metode lainnya. Hal ini karena konsep AHP mendasarkan analisisnya pada persepsi subjektif masyarakat, pakar, dan pelaku pasar. Dengan demikian, AHP membutuhkan partisipasi aktif masyarakat dalam proses identifikasi komoditas unggulan. Partisipasi masyarakat sangat diperlukan untuk mencapai keberhasilan pembangunan ekonomi. Rahman (1995) membuktikan dalam studinya bahwa pengembangan partisipasi masyarakat tidak hanya efektif dalam mengurangi kemiskinan tapi juga berkontribusi subtansial dalam mendorong tingkat pertumbuhan ekonomi. Dengan pelibatan masyarakat dalam proses identifikasi komoditas unggulan desa, diharapkan partisipasi masyarakat itu akan tetap bertahan setelah BUMDes didirikan. 
Motivasi utama pendirian BUMDes dalam UU Nomor 6 tahun 2014 adalah untuk memberdayakan masyarakat desa dengan memanfaatkan potensi sumber daya alam desa yang melimpah. Dengan demikian, partisipasi masyarakat dalam BUMDes adalah mutlak diperlukan, baik dalam proses perencanaan, pelaksanaan, maupun evaluasi program-program BUMDes. Hal ini diatur dalam UU Desa dengan pernyataan: "desa dapat mendirikan BUMDes" yang bermakna bahwa pengembangan BUMDes merupakan kewenangan dan prakarsa desa secara mandiri dan partisipatif (Kementerian PDT, 2015). Beberapa BUMDes yang menjadi percontohan nasional bergerak pada bidang usaha yang sesuai dengan potensi, keunggulan dan kebutuhan masyarakat setempat. Selain itu BUMDes-BUMDes tersebut juga sukses karena pengelola BUMDes berhasil memaksimalkan tingkat partisipasi masyarakat dalam setiap tahap aktivitas usaha BUMDes sebagaimana ditunjukkan oleh studi Tama dan Yanuardi (2013) di Gunung Kidul.

Desa Semamung di Kabupaten Sumbawa Provinsi Nusa Tenggara Barat merupakan salah satu desa yang tengah berusaha untuk membangun BUMDes yang kuat dan dapat berkontribusi signifikan dalam meningkatkan kesejahteraan masyarakat. Secara umum desa ini terdiri dari 1.657 orang penduduk yang sebagian besar bekerja sebagai petani dan peternak (Pemdes Semamung, 2015). Sejak diberlakukannya UU Desa yang memberikan kewenangan kepada pemerintah desa untuk mengelola uang transfer dari pusat, pemerintah desa bersama masyarakat bersepakat untuk membentuk dan mengembangkan BUMDes meski belum mengetahui akan bergerak dalam bidang usaha apa. Hasil penelitian ini akan membantu pemerintah dan masyarakat Desa Semamung untuk mengidentifikasi apa komoditas unggulan desa mereka dan akan menjadikannya sebagai dasar dalam menentukan bidang usaha yang akan digeluti oleh BUMDes. Dengan begitu diharapkan BUMDes dapat meningkatkan taraf hidup dan kesejahteraan masyarakat Desa Semamung.

\section{Metode Penelitian}

Penelitian ini akan menggunakan model penelitian kualitatif dan kuantitatif sekaligus atau biasa disebut dengan metode campuran (mix method) yang akan disajikan secara deskriptif. Model ini biasa digunakan untuk mendapatkan kesimpulan penelitian dari persepsi para stakeholder mengenai suatu fenomena, peristiwa, atau gejala sosial di masyarakat. Metode campuran ini sengaja dipilih sebagai model penelitian ini karena metode ini memungkinkan peneliti untuk memahami pendapat masyarakat mengenai potensi desa mereka. Membantu masyarakat untuk menemukan potensi desanya berdasarkan pendapat mereka sendiri merupakan salah satu modal penting dalam melakukan suatu program pembangunan pedesaan. Persepsi masyarakat itu kemudian akan dikuantifikasi secara proporsional untuk membuat gambaran atau deskripsi mengenai peubah yang diamati.

Teknik analisis komoditas unggulan yang akan digunakan adalah teknik scoring melalui metode Analisis Hirarki Proses (AHP). Dengan metode ini, komoditas unggulan ditetapkan berdasarkan kriteria yang dibobot menurut pendapat para pakar pembangunan ekonomi, serta dilengkapi dengan persepsi masyarakat, pemerintah setempat, dan pelaku ekonomi tentang potensi investasi, potensi pasar, dan potensi sumber daya alam di desa tersebut. Dengan pendekatan ini, persepsi para pakar pembangunan ekonomi, pengambil kebijakan (pemerintah), masyarakat, dan para pelaku ekonomi akan diselaraskan guna menemukan keunggulan dan potensi Desa Semamung.
Data dalam penelitian ini dikumpulkan melalui wawancara dengan bantuan kuisioner. Wawancara dilakukan secara berjenjang dimana wawancara pertama dilakukan dengan para pakar pembangunan ekonomi desa, LSM dan praktisi pembangunan desa. Proses penentuan pakar ini akan ditetapkan dengan teknik bola salju (snow ball technique). Teknik ini dilakukan dengan terlebih dahulu menetapkan seorang responden dari unsur pakar dengan metode purposive sampling. Selanjutnya responden yang terpilih tersebut akan dimintai saran mengenai responden dari unsur pakar berikutnya. Proses yang sama akan dilakukan pada responden terpilih berikutnya. Proses ini akan terus berlangsung hingga mencapai titik saturasi, yaitu titik dimana informasi yang didapatkan dari responden pakar sudah dianggap cukup. Konsep ini dapat dianalogikan seperti proses pembuatan bola salju dimana semakin lama digelinding, bola saljunya akan menjadi semakin besar.

Selanjutnya, informan dari unsur pengambil kebijakan ditetapkan dengan menggunakan metode purposive sampling. Metode ini mengharuskan pemilihan informan dilakukan atas dasar kriteria tertentu (Nazir, 2003). Kriteria informan dari unsur pengambil kebijakan ini adalah bahwa informan yang dimaksud haruslah sedang memegang jabatan publik strategis di pemerintahan desa maupun kecamatan. Sementara itu, responden dari unsur pelaku usaha di pedesaan serta masyarakat desa secara umum dilakukan dengan pendekatan multistage random sampling. Dengan metode ini, responden dipilih secara acak proporsional terhadap sebaran wilayah dusun dan lingkungan di lokasi penelitian.

Komoditas unggulan dalam penelitian ini dapat berupa komoditas pertanian dalam arti luas, komoditas industri, komoditas jasa ataupun komoditas yang tersedia secara bebas di alam. Komoditas yang terpilih sebagai komoditas unggulan melalui penelitian ini akan menjadi bahan untuk menciptakan produk utama BUMDes Semamung. Produk utama yang dimaksud merupakan hasil dari proses peningkatan nilai tambah yang dilakukan oleh BUMDes terhadap komoditas unggulan terpilih. BUMDes yang dimaksud dalam penelitian ini adalah badan usaha yang didirikan oleh masyarakat desa dengan Kepala Desa sebagai penanggungjawabnya. BUMDes yang dirujuk dalam penelitian ini sepenuhnya merupakan BUMDes yang berada di Desa Semamung, Kecamatan Moyo Hulu Kabupaten Sumbawa. Saat ini, BUMDes tersebut belum resmi berdiri, namun telah membentuk panitia persiapan pendirian BUMDes yang akan menjadi mitra dalam pelaksanaan penelitian ini. Meskipun terdapat program peningkatan nilai tambah produk desa melalui BUMDes, penelitian ini dibatasi sampai ditemukannya komoditas unggulan desa. Adapun teknis peningkatan nilai tambah tersebut tidak dikaji dalam penelitian ini.

Daryanto dan Hafizrianda (2010) menjelaskan bahwa ada tiga tahap yang harus dilalui dalam melakukan analisis data guna menemukan komoditas unggulan suatu wilayah menggunakan metode AHP, yaitu: (1) menetapkan kriteria-kriteria komoditas unggulan berdasarkan persepsi dari para pakar pembangunan pedesaan; (2) menentukan komoditas unggulan menurut persepsi pengambil kebijakan berdasarkan kriteria yang dibuat dalam tahap pertama; dan (3) melakukan konfirmasi mengenai komoditas unggulan menurut pengambil kebijakan tersebut kepada para pelaku atau penggerak perekonomian desa dan masyarakat desa secara umum. Berikut adalah metode analisis data dalam setiap tahap tersebut: 
(1) Penetapan serta pembobotan kriteria komoditas unggulan

(2) Penentuan komoditas unggulan

(3) Konfirmasi dan penetapan komoditas unggulan terpilih.

\section{Pembahasan}

\section{A. Penentuan Bobot Kriteria Komoditas Unggulan}

Langkah pertama yang dilakukan dalam prosedur AHP adalah mengidentifikasi dan membobot nilai kepentingan dari kriteria komoditas unggulan. Terdapat 10 kriteria komoditas unggulan (Daryanto dan Hafizrianda, 2010) yang digunakan dalam penelitian ini, yaitu:

1. Ketersediaan Sumber Daya Alam (SDA)

2. Ketersediaan Input Buatan (IB)

3. Ketersediaan Sumber Daya Manusia (SDM)

4. Potensi pengembangan dalam skala ekonomi/industri (SE)
5. Penyerapan Tenaga Kerja (TK)

6. Potensi Pasar Lokal (PL)

7. Potensi Pasar Ekspor (PE)

8. Kemudahan Investasi (I)

9. Ketersediaan Teknologi (T)

10. Dukungan Kelembagaan (K).

Pembobotan nilai kepentingan dari masing-masing kriteria diatas didasarkan pada persepsi pakar yang terdiri dari unsur akademisi, pengambil kebijakan, pembuat regulasi, dan NGO yang relevan. Berdasarkan hasil wawancara dengan 8 pakar utama, didapatkan hasil pembobotan kriteria komoditas unggulan sebagai mana ditunjukkan dalam tabel 1 berikut:

Tabel 1. Bobot Kriteria Komoditas Unggulan menurut pakar

\begin{tabular}{|c|c|c|c|c|}
\hline No & Kode & Kriteria & Bobot & Ranking \\
\hline 1 & SDA & Sumber daya alam & 0,079 & 6 \\
\hline 2 & IB & Input Buatan & 0,062 & 9 \\
\hline 3 & SDM & Sumber Daya Manusia & 0,202 & 1 \\
\hline 4 & SE & Skala Ekonomi & 0,127 & 3 \\
\hline 5 & TK & Tenaga Kerja & 0,111 & 4 \\
\hline 6 & $\mathrm{PL}$ & Pasar Lokal & 0,043 & 10 \\
\hline 7 & $\mathrm{PE}$ & Pasar Ekspor & 0,072 & 8 \\
\hline 8 & 1 & Investasi & 0,098 & 5 \\
\hline 9 & $\mathrm{~T}$ & Teknologi & 0,129 & 2 \\
\hline 10 & $\mathrm{~K}$ & Kelembagaan & 0,077 & 7 \\
\hline & & Total $=$ & \multicolumn{2}{|l|}{1,000} \\
\hline & & Global Consistency Index $(\mathrm{GCI})=$ & \multicolumn{2}{|l|}{0,11} \\
\hline
\end{tabular}

Sumber: Data Primer diolah, 2018

Tabel diatas menunjukkan bahwa para pakar menempatkan aspek SDM sebagai kriteria utama dalam penentuan komoditas unggulan dengan bobot 0,202 (20,2\%), sedangkan kriteria yang dianggap paling tidak penting adalah ketersediaan pasar lokal yang bobotnya sebesar $0,043(4,3 \%)$. Hal ini bermakna bahwa penetapan komoditas unggulan itu nantinya akan dipengaruhi oleh 20,2\% unsur ketersediaan SDM, 4,3\% pasar lokal, dan sisanya oleh kriteria lainnya sebesar angka yang ada pada tabel diatas.

SDM dalam hal ini didefinisikan sebagai tingkat penguasaan atau pengetahuan masyarakat mengenai teknologi, keterampilan, akses pasar, dan manajemen terhadap suatu komoditas tertentu. Tabel diatas menegaskan bahwa SDM adalah aspek paling penting dalam menentukan komoditas unggulan lalu disusul secara berurutan oleh aspek ketersediaan teknologi, potensi pengembangan skala ekonomi, penyerapan tenaga kerja, kemudahan investasi, dan lain-lain. Global
Consistency Index (GCI) dalam tabel tersebut menunjukkan koefisien kelogisan persepsi pakar. Semakin kecil GCI, semakin baik tingkat konsistensi pakar. Dalam penelitian ini, standar GCI yang dijadikan acuan adalah maksimal 0,20 (20\%). Nilai GCI 0,11 dalam tabel diatas menunjukkan bahwa persepsi para pakar mengenai bobot kepentingan kriteria komoditas unggulan menggunakan prosedur AHP ini sudah baik.

\section{B. Focus Group Discussion (FGD)}

FGD ini dilakukan untuk menyusun daftar alternatif komoditas unggulan yang akan menjadi pilihan para responden. FGD ini dihadiri oleh Kepala Desa, Kepala Dusun, pimpinan dan anggota BPD, serta tokoh-tokoh masyarakat setempat di Desa Semamung. FGD tersebut menghasilkan beberapa alternatif komoditas unggulan, yaitu:

1. Kategori Pertanian Sawah

a. Padi 

b. Kacang Hijau
c. Kedelai
d. Jagung

2. Kategori Pertanian Non Sawah
a. Beternak Sapi
b. Berburu Madu Hutan
c. Berkebun Kayu Jati
d. Budidaya Jamur Tiram

3. Kategori Jasa
a. Jasa Laundry
b. Jasa Transportasi
c. Jasa Bank Sampah
d. Jasa Wisata

\section{Penentuan Komoditas Unggulan}

Setelah alternatif komoditas unggulan itu ditetapkan melalui FGD, selanjutnya dilakukan interview dengan responden yang terdiri dari para penduduk desa. Interview ini dilakukan untuk mengetahui persepsi masyarakat mengenai komoditas unggulan yang ada di desa mereka. Keputusan mengenai komoditas unggulan terpilih dianalisa menggunakan metode AHP. Langkah utama dalam prosedur ini adalah melakukan pembobotan sebagaimana yang dilakukan saat penentuan bobot kriteria komoditas unggulan. Pembobotan itu dilakukan pada setiap item kriteria yang telah ditetapkan pada langkah sebelumnya. Selanjutnya, hasil pembobotan itu dikalikan dengan nilai bobot dari kriteria masing-masing. Hasil penjumlahan dari hasil perkalian antara bobot kepentingan komoditas unggulan dengan bobot kepentingan kriteria itulah yang kemudian menjadi dasar untuk menetapkan komoditas unggulan pada masing-masing kategori. Berikut adalah hasil pembobotan komoditas unggulan pada masing-masing kategori.

Tabel 2. Bobot Komoditas Unggulan Kategori Pertanian Sawah

\begin{tabular}{|c|c|c|c|c|c|c|c|c|c|c|c|c|}
\hline \multirow[b]{2}{*}{ Komoditas } & \multicolumn{10}{|c|}{ Bobot } & \multirow[b]{2}{*}{$\begin{array}{l}\text { Bobot } \\
\text { Total }\end{array}$} & \multirow[b]{2}{*}{ Ranking } \\
\hline & $\begin{array}{l}\text { SDA } \\
0,079 \\
\end{array}$ & $\begin{array}{c}\text { IB } \\
0,062 \\
\end{array}$ & $\begin{array}{l}\text { SDM } \\
0,202 \\
\end{array}$ & $\begin{array}{c}\text { SE } \\
0,127\end{array}$ & $\begin{array}{c}\text { TK } \\
\mathbf{0 , 1 1 1} \\
\end{array}$ & $\begin{array}{c}P L \\
0,043\end{array}$ & $\begin{array}{c}\text { PE } \\
0,072\end{array}$ & $\begin{array}{c}1 \\
0,098 \\
\end{array}$ & $\begin{array}{c}T \\
0,129 \\
\end{array}$ & $\begin{array}{c}K \\
0,077 \\
\end{array}$ & & \\
\hline Padi & 0,598 & 0,574 & 0,602 & 0,553 & 0,472 & 0,536 & 0,499 & 0,326 & 0,558 & 0,444 & 0,52415 & 1 \\
\hline Kacang Hijau & 0,143 & 0,124 & 0,162 & 0,173 & 0,121 & 0,13 & 0,142 & 0,329 & 0,147 & 0,121 & 0,16345 & 3 \\
\hline Kedelai & 0,056 & 0,059 & 0,07 & 0,065 & 0,073 & 0,054 & 0,065 & 0,185 & 0,071 & 0,069 & 0,07818 & 4 \\
\hline \multirow[t]{2}{*}{ Jagung } & 0,203 & 0,243 & 0,166 & 0,209 & 0,334 & 0,28 & 0,294 & 0,16 & 0,224 & 0,366 & 0,23422 & 2 \\
\hline & 1 & 1 & 1 & 1 & 1 & 1 & 1 & 1 & 1 & 1 & 1,00 & \\
\hline $\begin{array}{r}\text { Global } \\
\text { Consistency } \\
\text { Index (GCl) }\end{array}$ & 0,2 & 0,14 & 0,16 & 0,1 & 0,13 & 0,18 & 0,15 & 0,08 & 0,1 & 0,06 & & \\
\hline
\end{tabular}

Sumber: Data Primer Diolah, 2018

Tabel 2 diatas menunjukkan bahwa dari seluruh kriteria komoditas unggulan yang digunakan dalam penelitian ini, komoditas Padi dianggap responden sebagai komoditas yang paling unggul dalam kategori pertanian sawah. Komoditas Padi ini pada sebagian besar kriteria mendapat bobot lebih dari 0,50 (50\%) yang bermakna bahwa dibanding komoditas lainnya, Padi itu lebih unggul dengan bobot diatas 50\%. Adapun skor atau bobot total dari komoditas Padi adalah 0,524 (52,4\%) yang merupakan nilai tertinggi dibanding komoditas Kacang Hijau, Kedelai dan Jagung yang secara berturut-turut memiliki total bobot sebesar 0,163 (16,3\%); 0,078 (7,8\%); dan 0,234 (23,4\%).
Hal ini berarti bahwa alternatif komoditas unggulan kedua setelah Padi adalah Komoditas Jagung, sedangkan komoditas yang dianggap responden sebagai paling tidak unggul adalah Komoditas Kedelai. Global Consistency Index (GCI) merupakan sebuah index untuk mengukur tingkat validitas dan konsistensi argumen responden dalam penelitian. Semakin tinggi GCI, semakin tidak valid hasil analisis karena argumen responden menjadi terlalu beragam, demikian juga sebaliknya. Dalam penelitian ini, standar nilai GCI maksimum yang dapat ditorerir adalah $0,2(20 \%)$. 
Tabel 3. Bobot Komoditas Unggulan Pada Kategori Pertanian Non Sawah

\begin{tabular}{|c|c|c|c|c|c|c|c|c|c|c|c|c|}
\hline \multirow{3}{*}{ Komoditas } & \multicolumn{10}{|c|}{ Bobot } & \multirow{3}{*}{$\begin{array}{c}\text { Bobot } \\
\text { Total }\end{array}$} & \multirow{3}{*}{ Ranking } \\
\hline & SDA & IB & SDM & SE & TK & PL & PE & $\mathbf{I}$ & $\mathbf{T}$ & K & & \\
\hline & 0,079 & 0,062 & 0,202 & 0,127 & 0,111 & 0,043 & 0,072 & 0,098 & 0,129 & 0,077 & & \\
\hline Beternak Sapi & 0,594 & 0,53 & 0,58 & 0,611 & 0,438 & 0,6 & 0,561 & 0,248 & 0,495 & 0,59 & 0,52294 & 1 \\
\hline $\begin{array}{l}\text { Berburu Madu } \\
\text { Hutan }\end{array}$ & 0,097 & 0,118 & 0,089 & 0,097 & 0,161 & 0,112 & 0,132 & 0,295 & 0,135 & 0,102 & 0,13165 & 3 \\
\hline $\begin{array}{l}\text { Berkebun Kayu } \\
\text { Jati }\end{array}$ & 0,221 & 0,242 & 0,237 & 0,196 & 0,213 & 0,2 & 0,226 & 0,215 & 0,251 & 0,192 & 0,22198 & 2 \\
\hline \multirow[t]{2}{*}{$\begin{array}{l}\text { Budidaya Jamur } \\
\text { Tiram }\end{array}$} & 0,088 & 0,11 & 0,094 & 0,096 & 0,188 & 0,088 & 0,081 & 0,242 & 0,119 & 0,116 & 0,12344 & 4 \\
\hline & 1 & 1 & 1 & 1 & 1 & 1 & 1 & 1 & 1 & 1 & 1,00 & \\
\hline $\begin{array}{r}\text { Global } \\
\text { Consistency } \\
\text { Index (GCI) }\end{array}$ & 0,1 & 0,18 & 0,14 & 0,16 & 0,05 & 0,13 & 0,12 & 0,03 & 0,1 & 0,05 & & \\
\hline
\end{tabular}

Sumber: Data primer diolah, 2018

Sedangkan dalam kategori Pertanian Non Sawah, Beternak Sapi dianggap sebagai komoditas paling unggul oleh masyarakat dengan bobot total 0,523 (52,3\%). Sebagaimana komoditas Padi pada kategori Pertanian Sawah, Komoditas Beternak Sapi pada kategori Pertanian Non Sawah ini juga mendominasi keunggulan pada semua kriteria yang telah ditetapkan oleh pakar. Hal ini dapat dipahami mengingat aktifitas beternak sapi merupakan usaha pedesaan yang diusahakan secara turun temurun oleh masyarakat. Adapun alternatif komoditas unggulan kedua untuk kategori pertanian non sawah ini adalah Berkebun Jati dengan bobot total sebesar $0,222(22,2 \%)$. Sedangkan Budidaya Jamur Tiram yang merupakan komoditas baru bagi masyarakat Semamung dianggap paling tidak unggul oleh responden pada kategori ini dengan nilai bobot hanya $0,123(12,3 \%)$. Hal ini disebabkan karena banyak responden yang belum mengenal dengan baik potensi ekonomi dan skill teknis budidaya jamur tiram. Nilai index konsistensi yang lebih rendah dari 0,2 (20\%) pada semua kriteria menunjukkan bahwa persepsi responden dalam persoalan ini relatif seragam.

Tabel 4. Bobot Komoditas Unggulan Kategori Jasa

\begin{tabular}{|c|c|c|c|c|c|c|c|c|c|c|c|c|}
\hline \multirow{3}{*}{ Komoditas } & \multicolumn{10}{|c|}{ Bobot } & \multirow{3}{*}{$\begin{array}{l}\text { Bobot } \\
\text { Total }\end{array}$} & \multirow{3}{*}{ Ranking } \\
\hline & SDA & IB & SDM & SE & TK & PL & PE & I & $T$ & K & & \\
\hline & 0,079 & 0,062 & 0,202 & 0,127 & 0,111 & 0,043 & 0,072 & 0,098 & 0,129 & 0,077 & & \\
\hline Jasa Laundry & 0,312 & 0,358 & 0,358 & 0,371 & 0,345 & 0,337 & 0,265 & 0,399 & 0,338 & 0,335 & 0,34664 & 1 \\
\hline Jasa Transportasi & 0,408 & 0,378 & 0,344 & 0,302 & 0,279 & 0,351 & 0,345 & 0,204 & 0,391 & 0,276 & 0,32610 & 2 \\
\hline & 1 & 1 & 1 & 1 & 1 & 1 & 1 & 1 & 1 & 1 & 1,00 & \\
\hline $\begin{array}{r}\text { Global Consistency } \\
\text { Index (GCI) }\end{array}$ & 0,02 & 0,03 & 0,03 & 0,02 & 0,02 & 0,06 & 0,02 & 0,07 & 0,07 & 0,02 & & \\
\hline
\end{tabular}

Sumber: Data primer diolah, 2018

Meski tidak unggul secara mutlak pada seluruh kriteria sebagaimana komoditas Padi pada kategori Pertanian Sawah dan komoditas Beternak Sapi pada kategori Pertanian Non Sawah, namun secara keseluruhan, Jasa Laundry dianggap responden sebagai komoditas jasa paling unggul dengan bobot total $0,347(34,7 \%)$. Selanjutnya disusul oleh komoditas Jasa Transportasi dengan bobot total 0,326 (32,6\%). Secara keseluruhan, bobot kepentingan kedua jenis jasa itu memang tidak terlalu jauh. Kalau kita lihat lebih detail per kriteria, komoditas Jasa Transportasi sebenarnya unggul dalam 5 kriteria yaitu SDA, IB, PL, PE, dan T. Sedangkan komoditas Jasa Laundry unggul di 5 kriteria lainnya, yakni SDM, SE, TK,
I, dan K. Dari sini terlihat bahwa komoditas jasa Laundry unggul pada kriteria-kriteria yang memiliki bobot kepentingan yang lebih besar berdasarkan persepsi pakar. Sementara itu, jasa wisata diangggap sebagai komoditas jasa paling tidak unggul dengan bobot total sebesar 0,13 (13\%). Hal ini dapat dimaklumi mengingat potensi-potensi wisata di Desa Semamung belum terekspose dan tereksploitasi secara baik. Nilai GCI pada kategori ini seluruhnya dibawah 0,1 (10\%) yang berarti tingkat keseragaman jawaban responden sangat tinggi. Dengan demikian, informasi yang didapat dari responden sangat valid. 


\section{Kesimpulan}

Dari 10 kriteria komoditas unggulan, responden pakar dalam penelitian ini memberikan bobot penilaian paling tinggi kepada kriteria Sumber Daya Manusia (SDM) dengan total bobot sebesar 0,202 (20,2\%), disusul oleh kriteria Teknologi (T) dan Skala Ekonomi (SE) masing-masing sebesar 0,129 $(12,9 \%)$ dan $0,127(12,7 \%)$. Adapun kriteria dengan bobot terendah adalah kriteria Pasar Lokal (PL) dengan bobot hanya 0,043 (4,3\%).

Berdasarkan nilai perkalian antara bobot kepentingan komoditas dengan bobot kriteria tersebut, maka komoditas unggulan untuk kategori Pertanian Sawah adalah komoditas Padi dengan total bobot sebesar 0,524 (52,4\%). Selanjutnya untuk kategori pertanian non sawah, komoditas unggulannya adalah Beternak Sapi dengan total bobot sejumlah 0,523 $(52,3 \%)$. Terakhir, komoditas unggulan pada kategori jasa adalah Jasa Laundry yang memiliki bobot total sebesar 0,347 (34,7\%). Adapun nilai Global Consistency Index (GCI) untuk semua kategori tersebut adalah dibawah 0,2 (20\%) yang artinya data yang didapat dari responden dinyatakan valid dan relatif seragam.

Dengan demikian, agar keberadaan Badan Usaha Milik Desa (Bumdes) di Semamung dapat mengundang partisipasi optimum dari masyarakat serta dapat memajukan kesejahteraan masyarakat, maka BUMDes tersebut perlu bergerak dalam bidang usaha yang berkaitan dengan Komoditas Padi, Beternak Sapi, dan Jasa Laundry.

\section{Daftar Pustaka}

Atmanti, Hastarini D. 2008. Analytical Hierarchy Process Sebagai Model yang Luwes. Prosiding INSAHP5 Teknik Industri Universitas Diponegoro: Semarang

Bachtiar, Imam. 2005. Developing Community Participation in a Developing Country: Case Studies in the Lombok Island, Indonesia. Book chapter edited by Mitsuda $\mathrm{H}$ and Sayuti RH. 2005. Sustainable Lombok: The Rich Nature and Rich People in the 21 st Century. Universitas Mataram Press; Mataram

Braverman, Avishay dan Guasch, J Luis. 1993. Administrative Failures in Rural Credit Program. Book chapter edited by Hoff K; Braverman A; dan Stiglitz JE. 1993. The Economics of Rural Organization: Theory, Practise and Policy. Oxford University Press: New York

Budiono, Puguh. 2015. Implementasi Kebijakan Badan Usaha Milik Desa (BUMDes) di Bojonegoro, Studi Kasus di Desa Ngringinrejo Kecamatan Kalitidu dan Desa Kedungprimpen Kecamatan Kanor. Jurnal Politik Muda, vol. 4 No. 1 pp.116-125

Daryanto H dan Hafizrianda Y. 2010. Model-Model Kuantitatif Untuk Perencanaan Pembangunan Ekonomi Daerah, Konsep dan Aplikasi. IPB Press: Bogor

Falatehan, A Farobi. 2016. Analytical Hierarchy Process (AHP), Teknik Pengambilan Keputusan Untuk Pembangunan Daerah. Indomedia Pustaka: Yogyakarta

Harjanti, IM; Astuti KD; dan Yesiana R. 2015. Pola Distribusi Komoditas Pertanian Unggulan di Desa Mlatiharjo Kecamatan Gajah Kabupaten Demak. Prosiding of
Confrence on Urban Studies and Development (CoUSD): Semarang

Haryanto T; Hidayati NA; dan Djoewito W. 2009. Ekonomi Pertanian. Airlangga University Press: Surabaya

Hendayana, Rachmat. 2003. Aplikasi Metode Location Quotient (LQ) Dalam Menentukan Komoditas Unggulan Nasional. Jurnal Informatika Pertanian vol 12 no. 1 pp. $1-21$

Kementerian Desa, Pembangunan Daerah Tertinggal dan Transmigrasi. 2015. Desa Membangun Indonesia; Buku 7 - Badan Usaha Milik Desa, Spirit Usaha Kolektif Desa. Kementan PDT RI: Jakarta

Kolopaking, Lala M dan Syaharbian, Rilfar. 2016. Mekanisme Perencanaan Desa Membangun dan Membangun Desa. Working Paper Pusat Pembangunan Pertanian dan Pedesaan (PSP3) IPB vol.1 No.1.

Kuncoro, Mudrajat. 2010. Dasar-Dasar Ekonomika Pembangunan. UPP STIM YKPN: Yogyakarta

Latifah, Siti. 2005. Prinsip-Prinsip Dasar Analytical Hierarchy Process. USU Repository: Medan

Nazir, Moh. 2003. Metode Penelitian. Ghalia Indonesia: Jakarta

Neldysavrino. 2007. Aksi Kolektif Perempuan Kelompok Dasa Wisma. Book chapter edited by Indriatmoko, Yayan. 2007. Dari Desa ke Desa, Dinamika Gender dam Pengelolaan Kekayaan Alam. Center for International Forestry Report (CIFOR): Bogor

Pemerintah Desa Semamung. 2015. Profil Desa Semamung Tahun 2015

Rahman, Muhammad A. 1995. Paricipatory Development, Toward Liberation or Co-optation. Book Chapter edited by Craig $G$ and Mayo M. 1995. Community Empowerment, A Reader in Participatory Development. Zed Books: London

Republik Indonesia, Peraturan Menteri Desa, Pembangunan Daerah Tertinggal dan Transmigrasi Nomor 4 Tahun 2015 tentang Pendirian, Pengurusan dan Pengelolaan, dan Pembubaran Badan Usaha Milik Desa.

Republik Indonesia, Undang-Undang Nomor 6 Tahun 2014 tentang Desa

Rustiadi E; Saifulhakim S dan Panuju DR. 2011. Perencanaan dan Pengembangan Wilayah. Crestpent Press: Jakarta

Sudantoko, H Djoko dan Mariyono, Joko. 2010. Tinjauan Teoritis Pembangunan Pedesaan yang Berkelanjutan: Pengentasan Kemiskinan dan Perbaikan Kualitas Lingkungan. Jurnal Jejak vol 3. No.2 pp.132-142.

Susilawati; Sastrawati, Isfa dan Wunas, Shirly. 2016. Penentuan Komoditas Unggulan Sektor Pertanian Tanaman Pangan di Kabupaten Bone, Sulawesi Selatan. Prosiding Temu Ilmiah PLBI 2016

Tama, Dantika OE dan Yanuardi. 2013. Dampak Badan Usaha Milik Desa (BUMDes) Bagi Kesejahteraan Masyarakat di Desa Karangrejek Kecamatan Wonosari Kabupaten Gunung Kidul. Laporan Hasil Penelitian Universitas Negeri Yogyakarta 
Tarigan, Robinson. 2002. Perencanaan Pembangunan Wilayah. Depdiknas: Jakarta

Todaro MP dan Smith SC. 2006. Pembangunan Ekonomi-edisi ke-9. Pearson Education: UK

Ulvianti, Fitri. 2014. Pengembangan Ekonomi Lokal Berdasarkan Sektor dan Komoditas Unggulan Tiap Desa di Pulau Poteran, Jawa Timur. Laporan Hasil Penelitian Jurusan Perencanaan Wilayah dan Kota, Institut Teknologi Sepuluh November (ITS): Surabaya
Yulaswati, Vivi dan Sumadi, Pungki. 2011. Reducing Poverty by Increasing Community and Female Participation. Book chapter edited by Manning, Chrish and Sumarto, Sadono. 2011. Employment, Living Standars, and Poverty in Contemporary Indonesia. Institute of Southeast Asian Studies (ISEAS) Publishing: Singapore 
Jurnal Ekonomi dan Bisnis Indonesia 